\section{The use of 31-gauge needles and syringes for intraocular injections}

\begin{abstract}
Purpose To describe the use of disposable 31-gauge needles for intraocular injections. Methods Description of the technique and photographs of the needles.

Results Patients feel the injection less and a smaller postinjection bleb is noted.

Conclusion Consideration should be given to the use of disposable 31-gauge needles or syringes for intraocular injections.

Eye (2007) 21, 829-830; doi:10.1038/sj.eye.6702514; published online 14 July 2006
\end{abstract}

Keywords: bevacizumab; intraocular; retina; injections; gauge

\section{Introduction}

Recently, there has been an increase in the use of therapeutic intraocular agents. Some of these agents are suspensions that are difficult to inject through small gauge needles, whereas others flow nicely through small gauge needles. Thirty-gauge needles are commonly used for injections of soluble agents because the smaller gauge causes less pain and tissue trauma. Recently, patients with diabetes have been using 31-gauge needles for insulin injections and blood glucose testing. We wish to describe the use of these needles for intravitreal injections (Figure 1a).

\section{Materials and methods}

Eyes that were enucleated were photographed with both needles (Figure 1b). Ten patients undergoing injections of bevacizumab were injected with 31-gauge needles. The 31-gauge $5 / 8^{\prime \prime}(8 \mathrm{~mm})$ needle comes attached to a $1 \mathrm{~cm}^{3}$ syringe (Becton-Dickinson Ultra-Fine II). The bevacizumab was transferred into the syringe by aspiration from the tip of another syringe
JS Pulido, CM Pulido, SJ Bakri, CA McCannel and JD Cameron
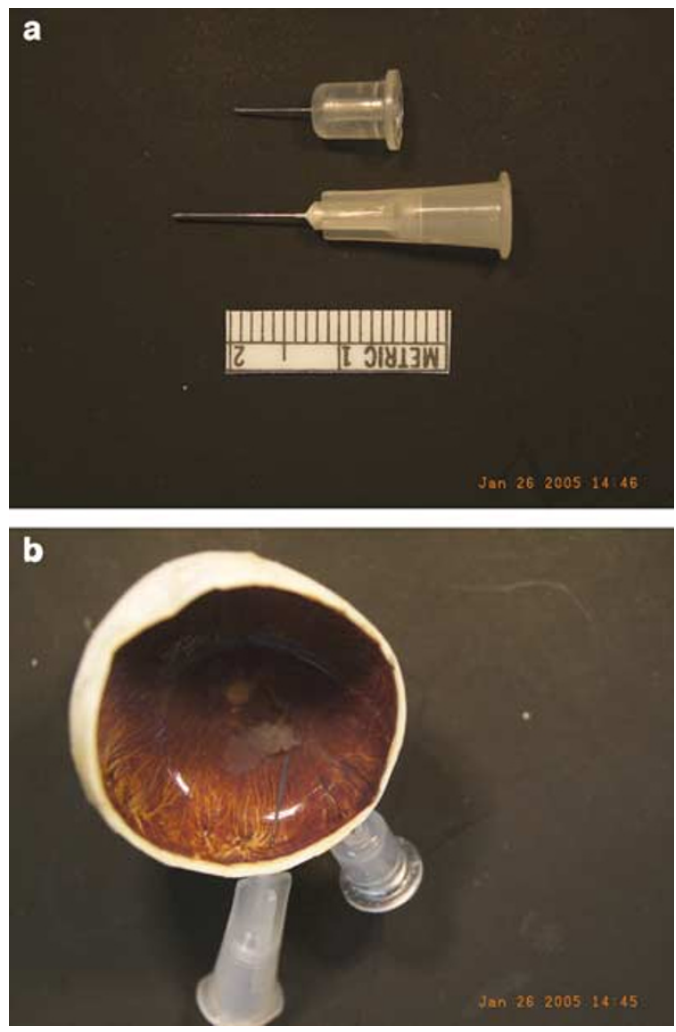

Figure 1 (a) A comparison of a 30- and a 31-gauge needle showing the difference in size and thickness. (b) A comparison of a 30- and a 31-gauge needle inserted into an enucleated eye.

that had been previously filled with an excess amount of drug, thereby not dulling the tip of the 31-gauge needle.

Patients who had undergone injections previously with the 30-gauge needles were asked their opinion as to whether this needle caused them less pain. The amount of reflux after the injection was qualitatively evaluated.

\section{Results}

Four patients had been previously injected with 30-gauge needles. All four patients rated the
Department of Ophthalmology, Mayo Clinic, Rochester, MN, USA

Correspondence: JS Pulido, Department of Ophthalmology, Mayo Clinic, 200 First St SW Rochester, MN 55905, USA Tel: + 1507284 3726; Fax: + 15072844612 E-mail: pulido.jose@ mayo.edu

Received: 24 March 2006 Accepted in revised form: 30 April 2006

Published online: 14 July 2006 
31-gauge injection as less painful. The amount of reflux was markedly less.

\section{Discussion}

A 27-gauge needle, a 30- gauge needle, and a 31-gauge needle have diameters of $0.41 \mathrm{~mm}, 0.31 \mathrm{~mm}$, and $0.26 \mathrm{~mm}$, respectively (Figure $1 \mathrm{~b}$ ). The 31-gauge needles have become standard practice for patients with diabetes mellitus for daily blood glucose monitoring and insulin injection. Smaller gauge needles have increased acceptance in diabetic patients, because they cause less pain and less tissue trauma. ${ }^{1}$ The newer technology small gauge needles have a larger lumen and thinner wall resulting in $40 \%$ lower flow resistance than standard needle technology. ${ }^{2}$ Because of increasing use of recurrent intraocular injections in patients with retinal diseases, use of 31-gauge needles over the present
27- and 30-gauge needles may allow patients to have less discomfort and a higher acceptance of these recurrent injections.

\section{Acknowledgements}

This work was supported in part by an unrestricted grant from Research to Prevent Blindness Inc., NY, USA.

\section{References}

1 Schwartz S, Hassman D, Shelmet J, Sievers R, Weinstein R, Liang $\mathrm{J}$ et al. A multicenter, open-label, randomized, twoperiod crossover trial comparing glycemic control, satisfaction, and preference achieved with a 31 gauge $\times 6 \mathrm{~mm}$ needle versus a 29 gauge $\times 12.7 \mathrm{~mm}$ needle in obese patients with diabetes mellitus. Clin Ther 2004; 26: 1663-1678.

2 Molin A, Larsen C, Lawton SA. Reduced flow resistance in insulin pen needles designed with thin wall technology. Diabetes 2002; 51: A475. 